\title{
Structure and architecture of a stromatolite from a Mediterranean stream
}

\author{
Sergi Sabater* \\ Departament d'Ecologia, University of Barcelona, Avgda. Diagonal 645, 08028 Barcelona, Spain
}

\begin{abstract}
The architecture of a riverine stromatolite ( 3 to $7 \mathrm{~mm}$ thick) was studied by means of scanning electron microscopy (SEM) of thin sections and confocal laser scanning microscopy (CLSM). The simultaneous use of the 2 techniques showed that the stromatolite is a highly porous structure, where ca $50 \%$ of the space is free of carbonated material. That area was slightly higher in the upper ( 46 to $57 \%$ ) than in the lower layer (39 to $44 \%$ ) of the stromatolite. Cyanobacterial cells and filaments, mucopolysaccharides and void spaces share that area. Filaments were present in the lowermost layer of the stromatolite, even though less densely arranged than in the upper layers. CLSM observations after staining with fluorescent probes (Concanavalin A) showed the existence of a huge network of exopolymers, mainly in the upper part of the structure. Cyanobacterial filaments were less abundant than mucilage in the lower layer ( 8.9 vs $17.6 \%$ ), this difference being more moderate in the upper layer ( 45 vs $33 \%$ ) of the stromatolite. The extensiveness of the exopolymer in the stromatolite may allow an extremely fast rewetting after desiccation and its survival after droughts. Spaces not occupied by mucilages and cells were much more abundant in the lower (ca $70 \%$ ) than in the upper layers (ca $20 \%$ ). The abundance of voids may be determinant of the diffusivity and adsorption capacity within the stromatolite, allowing allocation of resources (gases and nutrients) in the lowermost areas of the stromatolite. These structural characteristics help to understand the physiological adaptations observed in stromatolites inhabiting unfavourable environments.
\end{abstract}

KEY WORDS: Stromatolite - Confocal laser scanning microscopy - Scanning electron microscopy · Mediterranean · Oligotrophy · Desiccation · Mucopolysaccharides · Cyanobacteria

\section{INTRODUCTION}

Stromatolites are carbonated structures which are laminated and built by microbial communities (Winsborough \& Golubic 1987). These structures are associated with both physical and biological processes of mineral deposition (Merz 1992). Usually cyanobacteria are the most relevant biological component in these types of structure (Cohen \& Rosenberg 1989).

Stromatolites can develop in a variety of environments: marine (Pinckney et al. 1995), lacustrine (Osborne et al. 1982) and riverine (Kann 1978, Sabater 1989). In many cases, stromatolites grow in environments subjected to high temperatures (Aboal 1989, des Marais et al. 1989) and ionic content of the water

\footnotetext{
•E-mail: ssabater@porthos.bio.ub.es
}

(Winsborough \& Golubic 1987, Renaut 1993). The high plasticity and physiological adaptability of cyanobacteria (Stal 1995) support the development of stromatolites in extreme environments. The 3-dimensional character of stromatolites (Freytet \& Verrecchia 1998) possibly contributes to the physiological adaptations of cyanobacteria, by providing the allocation of resources, as well as the protection of their components. For instance, adaptation to nutrient limitation is shown by stromatolites in a variety of environments (Pinckey et al. 1995), and could be related to the storage capacity of organic matter, as well as to the internal diffusivity of the structure. Several observations show that this is the case in thinner and less complicated biological structures (Freeman \& Lock 1995, MassolDeyà et al. 1995).

Even though the existence of interstices has been revealed as an important structural feature in psam- 
mophilic crusts (Verrechia et al. 1995), it has never been explored in other biologically formed structures, such as stromatolites. The abundance of pores or channels, as well as of materials absorbing water (i.e. mucilages) can be relevant for the diffusion processes within the stromatolite, and may explain its physiological adaptations. This paper aims to show the abundance and distribution of these structural features in a riverine stromatolite which develops in an oligotrophic, semi-arid environment (Sabater et al. 2000). Two specific objectives are aimed at: (1) showing if cyanobacteria are distributed homogeneously within the stromatolite, and how they are related with other structural components of the crust, and (2) detecting whether mucilage and voids occur throughout the structure, quantitying their occurrence.

These objectives have to be pursued without altering the original architecture of the stromatolite. In this paper, the structure and architecture of a riverine stromatolite is approached by several complementary methods. Scanning electron microscopy (SEM) carried out in thin sections of the crust was used to determine the space fraction occupied by organisms and mucilages in intact surfaces of the stromatolite. Moreover, confocal laser scanning microscopy (CLSM) was used to investigate the occurrence and distribution of photoautotrophs in the stromatolite, particularly in the upper versus the lower layers, as well as the contribution of the mucilage material to the architecture of the whole structure. CLSM provides the opportunity to obtain sequential images and reconstruct 3-dimensional images of thick biofilms (Inoue 1990). These techniques add information on the structure of stromatolites to that obtained via classical light and electron (SEM, transmission) microscopy, which have proved useful in describing community composition (Jones et al. 1998) and architecture (Freytet \& Verrecchia 1998).

\section{MATERIALS AND METHODS}

The stromatolitic crust analyzed in this study was obtained from the calcareous Mediterranean stream La Solana. This stream is extensively covered on its bottom by a 3 to $9 \mathrm{~mm}$ thick stromatolitic crust (Sabater et al. 2000). Stromatolite collections were performed during June 1998, and material was stored until microscopical analysis.

Selected fragments of the stromatolite were observed under light microscopy (LM), SEM and CLSM. LM observations were carried out using a Reichert Polyvar equipped with Nomarski contrast. SEM observations were performed using a Hitachi S-2300 microscope equipped with backscattering electron detector (Robinson type). Complementary observations and electron dispersive $\mathrm{X}$-ray analysis (EDS) in the same material were carried out using a Cambridge Stereoscan Microscope S-120 equipped with a Link PCXA. For EDS observations, analyses were carried out on osmified fragments of the stromatolite. Osmification was used as a tool to identify labelled organic matter areas under EDS. Fragments were included in epoxy resin and blocks used to obtain transverse thin sections of the crust. These were afterwards covered with carbon and gold for SEM. Images obtained for whole transects were binarized, and later analyzed for resin-occupied or non-occupied surface areas using the IMAT program (University of Barcelona), working at a UNIXbased station. The percentage of resin-occupied areas was calculated from the binarized images.

A Leica True Confocal Scanner Microscope (TCS 4D) was used for CLSM. Observations were performed using live fragments of the stromatolite, separately for the upper and lower layers of intact stromatolitic patches with Rivularia (Rivularia community) and Schizothrix predominance (mixed community, Romaní \& Sabater 1998). Small fragments were transferred to microcapsules and observed at $20 \times$ and $40 \times$ objectives (numerical apertures 0.4 and 0.5 respectively). Small aperture objectives are indicated for observations on thick specimens and allow longer working distances, which are necessary in fully hydrated structures (Lawrence et al. 1998). Natural fluorescence of chlorophyllous pigments (568 nm excitation, $590 \mathrm{~nm}$ emission) was used as a tracer of the indepth distribution of algae and cyanobacteria.

Observations on mucilage distribution in CLSM were obtained after staining with succenemedyl-ester Concanavalin A (Succ-Con A, Molecular Probes, Inc.) at a final concentration of $20 \mu \mathrm{g} \mathrm{ml}^{-1}$. The use of fluoresceinconjugated lectins in cooperation with CLSM was used to locate the marked areas in fully hydrated samples (Wolfaardt et al. 1998). Stromatolite fragments were incubated in Succ-Con A solution for $30 \mathrm{~min}$ at ambient temperature $\left(18^{\circ} \mathrm{C}\right)$. After staining, the sample was washed 3 times with phosphate buffered saline (PBS) solution (adjusted $\mathrm{pH}$ of 7.4), after which the stromatolite was covered with PBS, and observed. Succ-Con A is a lectin which binds to certain carbohydrate residues with high specificity ( $\alpha$-D-mannose and $\alpha$-D-glucose, Schuessler et al. 1997). A $1 \%$ transmission for laser intensity with the pinhole set at its smallest aperture was sufficient for excitation of the fluor-conjugated lectins. Observations were performed at $488 \mathrm{~nm}$ excitation and $520 \mathrm{~nm}$ emission. Autofluorescence could not be detected at this setting, thus avoiding interference between the 2 signals. Simultaneous sampling for autofluorescence signal was achieved with a Double Dichroic (DD) filter.

Digital image analysis of CLSM sections was used to determine the relative area occupied by the exopolymer and cyanobacterial cells with respect to the total micro- 
scopic field area. Images obtained from the face and reverse of several spots of the stromatolite were analyzed to account for differences between the 2 extreme parts of the stromatolite. Reconstruction of pre-established series of 53 images per signal ( $3.2 \mu \mathrm{m}$ interval) was used to quantify the proportion of chlorophyll and exopolymeroccupied areas. The quantification was achieved by means of Metamorph software (v. 3.5, Universal Imaging Co.). To overcome the high spatial variation characteristic of the stromatolite, up to 24 fields in different areas of the stromatolite were examined. Observations were carried out at $20 \times$ magnification in order to include a higher area in the microscopical field.

\section{RESULTS}

Filamentous cyanobacteria, Schizothrix penicillata (Kütz.) Gom., S. affinis Lemm. and Rivularia biasolettiana Menegh., were dominant in the crust (Table 1). The 2 differently coloured layers which were macroscopically visible in a stromatolite section were characterised by a different proportion of chlorophyllous and carotenoid pigments (Guasch \& Sabater 1995), as well as by differences in the relative abundance of their components (Table 1). While $R$. biasolettiana was more prevalent in the upper fraction, Schizothrix spp. were dominant in the lower layer (Table 1). The proportion

Table 1. (a) General composition (\%) of algae and cyanobacteria in the upper and lower layers of the stromatolite in $\mathrm{La}$ Solana. (b) Algae and cyanobacteria observed in permanent patches that can be distinguished in the stromatolite, i.e. the mixed community and the Rivularia biasolettiana community

(a) Upper and lower layers

Algae and cyanobacteria

Upper layer Lower layer (green) (yellowish)

Cymbella sp. $\quad 0.3$

Chantransia sp.

Homoeothrix crustacea Woronich

Mougeotia sp.

Rivularia biasolettiana Menegh.

Schizothrix affinis Lemm.

$\begin{array}{ll}\text { Schizothrix affinis Lemm. } & 35.4 \\ \text { Schizothrix penicillata (Kütz.) Gom. } & 25.0\end{array}$
0.3

9.1

0.6

27.8
1.5

24.5

35.1

38.8

\section{(b) Permanent patches}

Algae and cyanobacteria

Mixed Rivularia community community

Cymbella sp. pl.

Chroococcus turgidus (Kütz.) Nägeli 6.7

Homoeothrix crustacea Woronich 3.3

Rivularia biasolettiana Menegh. $\quad 24.6$

Schizothrix affinis Lemm. $\quad 33.3$

Schizothrix penicillata (Kütz.) Gom. 22.0

Spirogyra sp.

Zygnema sp.

10.0 of the main components also differed between the permanent patches of the stromatolite (Table 1).

Zones with different electron densities revealed by the SEM on the thin section of the stromatolite (Fig. 1) corresponded to carbonated structures (whitish) and others occupied by the epoxy resin (greyish). The epoxy resin covered voids as well as other non-carbonated structures. Areas of intermediate electron density occurred among the epoxy resin (Fig. 1A,B), and corresponded to organisms and material of biological origin (Fig. 1A,B,C). Moreover, the carbonate structure was perforated by a high number of minuscule pores, of uncertain origin (Fig. 1D).

Most of the area occupied by the epoxy resin formed rounded and irregularly shaped areas, scattered between the carbonate areas (Fig. 1A,B). Most of the round forms corresponded to cyanobacterial filaments. Round shapes between 3 and $12 \mu \mathrm{m}$ diameter corresponded to groups of filaments of Schizothrix penicillata (Fig. 1A). Small groups of round areas ( 1.5 to $2 \mu \mathrm{m}$ diameter) corresponded to trichomes of $S$. affinis $(0.8$ to $1 \mu \mathrm{m}$ diameter), which form distinct groups of several trichomes included in the same carbonated matrix. Elongated structures corresponded to oblique or horizontal fragments of cyanobacterial filaments (Fig. 1B). Some of them, which occupied a high proportion of the upper layer of the crust (Fig. 1C), were filaments of Rivularia biasolettiana colonies. The $R$, biasolettiana filaments (resinoccupied spaces) were among their corresponding carbonated incrustations. The presence of filaments in these described areas was confirmed by EDS analysis, which detected osmium traces matching their shapes. Irregular areas, sometimes of amorphous shape, corresponded to empty spaces or mucilage-occupied areas (Fig. 1D).

The architecture of the crust became less definite towards the bottom layers (Fig. 2). In this part of the crust, areas of irregular shape (i.e. empty spaces or mucilageoccupied areas) were common and formed larger patches interspersed with carbonated areas. Round or elongated areas (related to cyanobacterial cells and filaments) were much scarcer. A rather continuous layer of resin-occupied spaces, also of amorphous shape, was apparent in a medium position (Fig. 2, arrow) and corresponded to the transition between the 2 layers of the stromatolite that can be observed macroscopically.

The percentage of the area occupied by the resin (i.e. the greyish patches, corresponding to biological entities or voids) was calculated by image analysis from 2 complete transverse transects carried out with the SEM at $60 \times$. The 2 transects corresponded to 2 different resin blocks (i.e. 2 different stromatolite fragments). From the analysis of the images, it was found that the surface area of resin-occupied patches ranged between 48 and $56 \%$ of the total considered. The percentage of the area occupied by resin-occupied spaces 


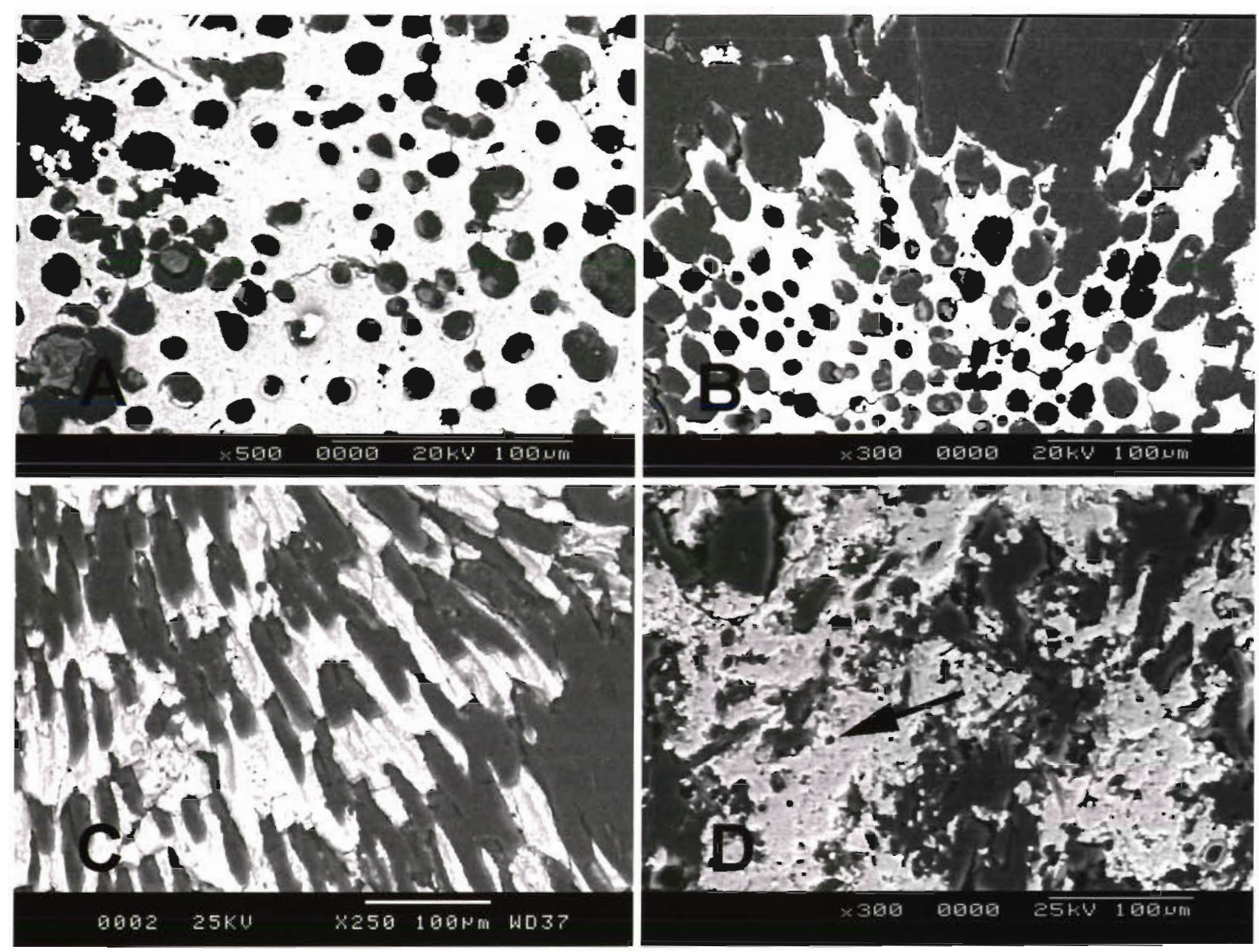

Fig. 1. SEM (backscattering) photographs obtained on transverse thin sections of La Solana stromatolite. Whitish colour corresponds to the carbonated areas. Greyish colour corresponds to areas embedded by epoxy resin. (A,B) Areas occupied by Schizothrix spp. filaments, in (A) a medium or (B) an upper position within the stromatolite, and the existence of areas of intermediate electron density in the resin-occupied zones, which likely correspond to cyanobacterial filaments. (C) A colony of Rivularia biasolettiana filaments emerging from their carbonated crusts. (D) Location of minuscule pores perforating the carbonated structure (arrow), as well as voids of amorphous shape between the carbonated areas

was slightly higher in the upper ( 46 to $57 \%$ ) than in the lower layer ( 39 to $44 \%$ ).

Observations with CLSM on fully hydrated live fragments of stromatolite showed remarkable differences in biological architecture and mucilage abundance between the upper and lower parts of the stromatolite (Fig. 3), Filaments were present in the lowermost layer of the stromatolite (Fig. 3A, C), even though less densely arranged than in the upper layers (Fig. 3E). Reconstruction of image sequences (covering a $160 \mu \mathrm{m}$ depth profile) for the 2 parts of the stromatolite also showed an apparent higher amount of mucopolysaccharides at the top (Fig. 3F) than at the bottom (Fig. 3B,D). Mucilage was closely associated to filaments in the upper layer (Fig. 3E,F), but seldom in the lower layers (Fig. 3C,D).
From the comparison of the 2 microscopy signals (autofluorescence and fluor-conjugated lectins) obtained by CLSM, the area occupied by filaments and mucilage was calculated. Filaments had a smaller area than that occupied by the mucilage at the 2 sides of the stromatolite. This difference between the 2 components (filaments vs mucilage) was 2 -fold in the lower layer ( 8.9 vs $17.6 \%$ ), and more moderate in the upper layer (45 vs $33 \%$ ).

\section{DISCUSSION}

The 2 different methodologies used in this paper to describe the ultrastructure of a stromatolite, even though approaching it in different dimensions (SEM, 


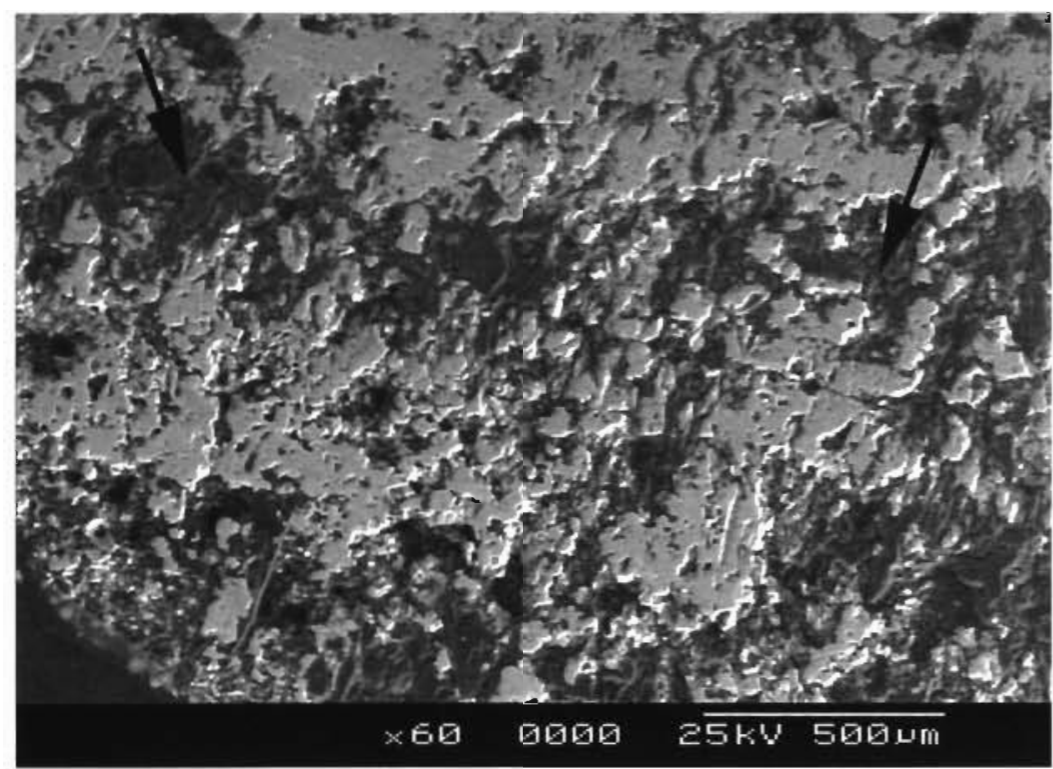

Fig. 2. SEM (backscattering) photograph on a transverse thin section of La Solana stromatolite, showing the aspect the lower two-thirds of the structure. The presence of a rather continuous layer of resin-occupied spaces in a medium position is indicated by arrows

2-dimensional; CLSM, 3-dimensional), shed light on the spatial arrangement of biological and non-biological components of the stromatolite. Non-carbonated materials occupy an important fraction (ca $50 \%$ ) of the whole surface area of the La Solana stromatolite (Fig. 2). Filaments, cells, mucilages and voids share this surface area. Cyanobacterial cells and filaments (together with their sheaths) were found all through the stromatolite, even in the lowermost part (Fig. 3A,C). This observation is in agreement with the fact that $75 \%$ of the total pigments in that part of the stromatolite were active chlorophylls (Guasch \& Sabater 1995). It can therefore be asserted that these cells were potentially photosynthetic, and that conditions in that part of the crust were suitable for them to remain permanently, in spite of the absence of light. It can be hypothesized that the existence of these filaments can guarantee re-colonization (Golubic 1973) in the case of severe damage to the upper layers of the stromatolite.

Stromatolites in calcareous Mediterranean streams show a wide array of functional adaptations that make them highly successful in the quasi-extreme conditions that characterize these systems (Sabater et al. 1995). Nutrient scarcity, as well as high irradiance and temperature, are characteristic descriptors of the systems where they develop (Sabater et al. 2000). The stromatolites are photosynthetically adapted to the high irradiances reaching the streambed (Guasch \& Sabater 1995), and possess the physiological mechanisms (nitrogen fixation, use of alternative phosphorus sources) to thrive under nutrient limitation (Sabater et al. 2000).

A striking adaptive feature of the stromatolite is its ability to overcome summer droughts, which put the different ecosystem components under strong hydric stress (Williams 1987). These periods can last for a long time in Mediterranean-type streams. Following desiccation, the stromatolite of La Solana breaks off into polygons, but quickly re-hydrates after a short pulse of incoming water. The physiological ability to recover was tested in a laboratory study (Romaní \& Sabater 1997), after a severe drought had affected La Solana in summer 1994 over a $40 \mathrm{~d}$ period. Exoenzymatic activities were the first to return to normal levels: $\beta$-glucosidase, $\beta$-xylosidase and phosphatase activities recovered within $3 \mathrm{~h}$. Photosynthetic activity (measured as $\mathrm{H}^{14} \mathrm{CO}_{3}$ incorporation) was noticeable after $1 \mathrm{~h}$ of rewetting, but the recovery time was longer $(5 \mathrm{~h}$ were not sufficient to record the pre-drought values). It can be assumed that this physiological plasticity is sustained by the structural characteristics of the stromatolite. The results of the present study indicate that the stromatolite forms an extensive exopolymeric network throughout the carbonated structure (Figs. $2 \& 3$ ). Mucopolysaccharidic material was more abundant in the upper layers, but it was also present in the lower layers of the stromatolite, making a decisive contribution to the extremely fast rewetting of the structure after desiccation (Romaní \& Sabater 1997).

Ability of stromatolites to thrive in nutrient-poor environments (Pinckney et al. 1995) is possibly related to the adsorption capacity of organic and inorganic molecules by the 3 -dimensional structure. The complex network of mucopolysaccharides, voids and live components, as well as of carbonaceous minerals, probably enhances the adsorption capacity (Costerton et al. 1987, Decho \& Herndl 1995) and subsequent use of resources by autotrophs and heterotrophs (Fiebig \& Marxsen 1992) within the stromatolite. Freeman \& Lock (1995) showed that exopolymers in the biofilm could successfully increase nutrient sorption by means of entrapment and ion exchange. High heterotrophic activity in La Solana is apparently disconnected from the DOC content of the water (Romani \& Sabater 1998), indicating that heterotrophic activities are mainly based on the utilization of the organic matter accumulated in the crust (Sabater et al. 2000). The La Solana stromatolite is a remarkable reservoir of organic matter, with carbon 

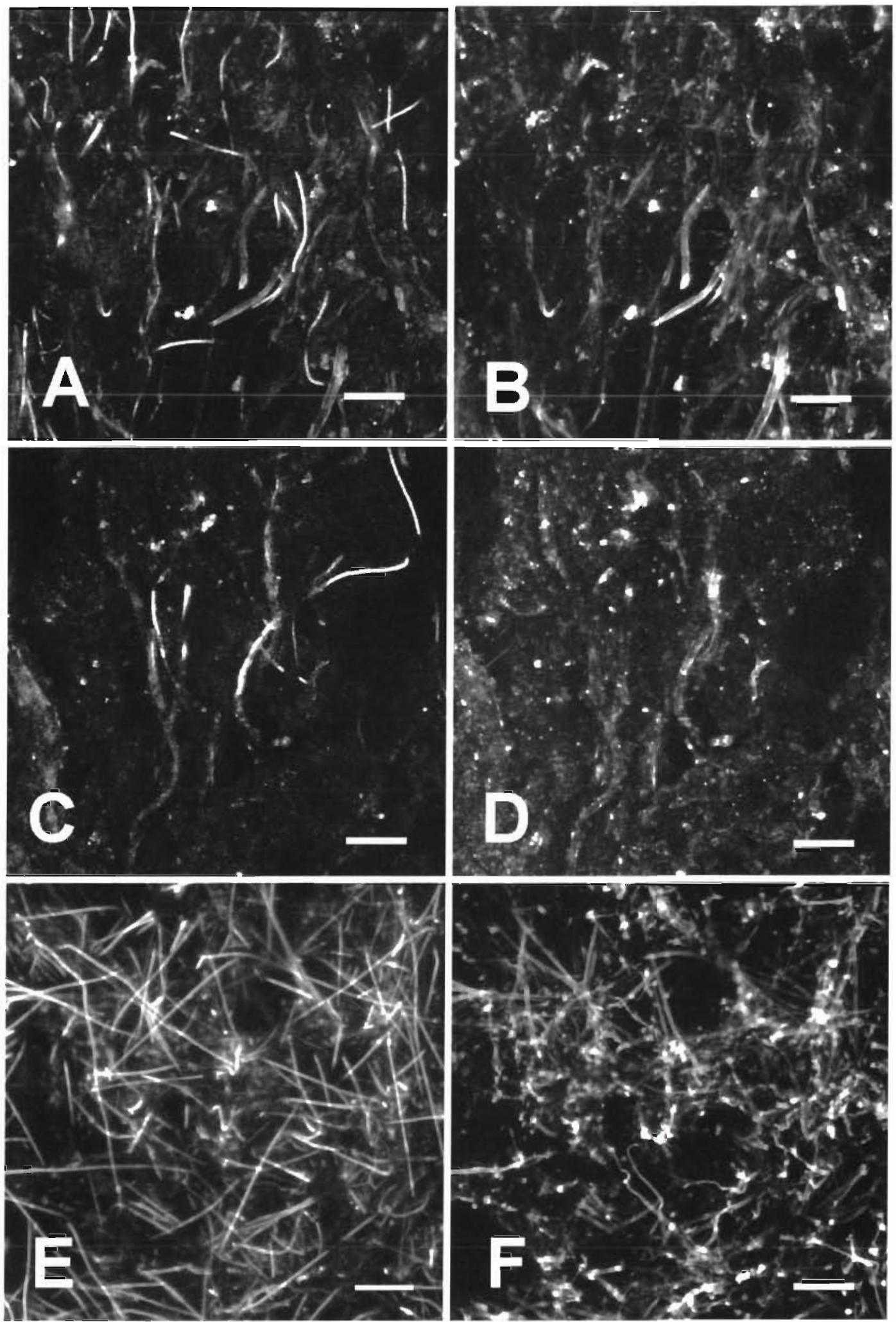

Fig. 3. $z$ series projection of the corresponding sequences of 53 images ( $3.2 \mu \mathrm{m}$ interval) obtained by CLSM in different positions of the stromatolite of La Solana. (A to D) Lower layer $(E, F)$ upper layer. Simultaneous sampling for autofluorescence and fluorescein-conjugated lectins for each area is shown by pairs: $(A, C, E)$ autofluorescence signal of chlorophyll (568 nm excitation, $590 \mathrm{~nm}$ emission); (B,D,F) mucopolysaccharide signal (488 nm excitation, $520 \mathrm{~nm}$ emission). Scale bars $=40 \mu \mathrm{m}$ 
accounting for an average proportion of $6 \%$ of dry weight. This accumulated material may provide an alternative source of organic carbon for the whole crust in unfavourable situations (e.g. low net community primary production; Guasch \& Sabater 1994).

CLSM observations have determined the existence of a remarkable number of live cells and filaments, as well as extensive mucilage in the lowermost stromatolite layer, but have also highlighted the existence of unoccupied spaces. The number of voids and interstices not occupied by the mucilage is much more extensive in the lower part of the structure. A high number of small pores were also visible with SEM on thin sections. Simple calculations from CLSM observations show that the spaces not occupied by mucilages and cells were much more abundant in the lower (ca $70 \%$ ) than in the upper layers (ca 20\%). In spite of the discrepancy between the quantification obtained by SEM and CLSM, the comparison between the 2 measurements confirms this assertion, since the proportion of carbonated areas was similar between the top and bottom layers. There is, therefore, an increasing gradient of void spaces from the top to the bottom of the stromatolite.

The 3-dimensional network of voids within the stromatolite probably facilitates the diffusion of all kind of substances through it. It can be assumed that the high number of interstices, occurring sometimes in spaces formerly occupied by mucilage and cells, may allow the movement of gases and fluids through them. Therefore these resources could reach areas far apart from the stream water layer. A sign of this homogeneity in resource distribution is that the stromatolite does not develop redox gradients which would be enhanced by low-diffusion situations (Stal 1995), and there are no signs that anaerobic metabolism could occur within it (Sabater et al. 2000). Indicating that this is not an isolated behaviour, Pinckney et al. (1995) did not observe anoxic microzones in a softer marine stromatolite. Interstices and pores in the stromatolites may operate analogously, but at a larger scale than the channels described by Neu \& Lawrence (1997) and Massol-Deyà et al. (1995) within bacterial biofilm structures of reactors and granulated carbon respectively. These channels have been described as the entrance gate to nutrients and gases from the upper to the bottom parts of biofilm (Lock 1993). The observation that there is a complex liquid flow in biofilm channels (Stoodley et al. 1994) implies that there is a contributing mechanism to molecular diffusion as the only internal mass transport. De Beer et al. (1994) showed that half of the total oxygen consumed by the biofilm was supplied by voids in the structure. This enhancement of transport within biofilms suggests that parts deeper than initially expected might still be functional.
At a larger scale, this assertion could be analogous for stromatolites, which, to a certain extent, could be considered as a special sort of thick biofilm. The same occurrence of active filaments in the bottom layers (Fig. 3A to D) suggests the existence of this transport. In the case of riverine stromatolites, such as that of La Solana, water velocity can enhance the diffusion of dissolved nutrients and gases throughout the whole structure (Stevenson \& Glover 1993). The boundary layer that limits diffusion decreases with fluid motion (Allan 1995), being inversely related to water velocity and therefore providing additional advantage in fast-flowing streams. Such a situation probably confers a unique character to the riverine stromatolites, in comparison with others developing elsewhere in marine and freshwater environments.

Acknowledgements. This research was funded by the CICYT of the Spanish Science Ministry (project number CL196-0874). Ramon Fontarnau and Susanna Castel (Serveis CientíficoTècnics, University of Barcelona) provided their expertise and creativity to the application of SEM and CLSM to the stromatolite description

\section{LITERATURE CITED}

Aboal M (1989) Epilithic algal communities from River Segura basin, southeastern Spain. Arch Hydrobiol 116:113-124

Allan JD (1995) Stream ecology. Structure and function of running waters. Chapman \& Hall, London

Cohen Y, Rosenberg E (1989) Microbial mats. Physiological ecology of benthic microbial communities. American Society for Microbiology, Washington

Costerton JW, Cheng KJ, Geesey GG, Ladd TI, Nickel JC, Dasgupta M, Marrie TJ (1987) Bacterial biofilms in nature and disease. Annu Rev Microbiol 41:435-464

de Beer D, Stoodley P, Roe F, Lewandowski Z (1994) Effect of biofilm structures on oxygen distribution and mass transport. Biotechnol Bioeng 43:1131-1138

Decho AW, Herndl GJ (1995) Microbial activities and the transformation of organic matter within mucilaginous material. Sci Total Environ 165:33-42

des Marais DJ, Cohen Y, Nguyen $H$, Cheatham M, Cheatham T, Muñoz E (1989) Carbon isotopic trends in the hypersaline ponds and microbial mats at Guerrero Negro, Baja California Sur, México: implications for Precambrian stromatolites. In: Cohen $Y$ (ed) Microbial mats: physiological ecology of benthic microbial communities. American Society for Microbiology, Washington, p 191-206

Fiebig DM, Marxsen J (1992) Immobilization and mineralization of dissolved free aminoacids by stream-bed biofilms. Freshw Biol 28:129-140

Freeman C, Lock MA (1995) The biofilm polysaccharide matrix: a buffer against changing organic substrate supply? Limnol Oceanogr 40:273-278

Freytet P, Verrecchia EP (1998) Freshwater organisms that build stromatolites: a synopsis of biocrystallization by prokaryotic and eukaryotic algae. Sedimentology 45:535-563

Golubic S (1973) The relationship between blue-green algae and carbonate deposits. In: Carr NG, Whitton BA (eds) The biology of blue-green algae. Blackwell, Oxford, p 434-472 Guasch H, Sabater S (1994) Primary production of epilithic 
communities in undisturbed Mediterranean streams. Verh Int Verein Limnol 25:1761-1765

Guasch H, Sabater S (1995) Seasonal variations in photosynthesis - irradiance responses by biofilms in Mediterranean streams. J Phycol 31:727-735

Inoue $\mathrm{S}$ (1990) Foundations of confocal scanned imaging in light microscopy. In: Pawley B (ed) Handbook of biological confocal microscopy. Plenum Press, New York, p 1-12

Jones B, Renaut RW, Rosen MR (1998) Microbial biofacies in hot-spring sinters: a model based on Ohaaki Pool, North Island, New Zealand. J Sediment Res 68:413-434

Kann E (1978) Typification of Austrian streams concerning algae. Verh Int Verein Limnol 20:1523-1526

Lawrence JR, Nie TR, Swerhone GDW (1998) Application of multiple parameter inaging for the quantification of algal, bacterial and exopolymer components of microbial biofilms. J Microbiol Methods 32:253-261

Lock MA (1993) Attached microbial communities in rivers, In: Ford TE (ed) Aquatic microbiology: an ecological approach. Blackwell, Oxford, p 113-138

Massol-Deyá AA, Whallon J, Hickey RF, Tiedje JM (1995) Channel structures in aerobic biofilms of fixed-film reactors treating contaminated groundwater. Appl Environ Microbiol 61:769-777

Merz M (1992) The biology of carbonate precipitation by cyanobacteria. Facies 26:81-102

Neu TR, Lawrence JR (1997) Development and structure of microbial biofilms in river water studied by confocal laser scanning microscopy. FEMS Microbiol Ecol 24:11-25

Osborne RH, Licari GR, Link MH (1982) Modern lacustrine stromatolites, Walker Lake, Nevada. Sediment Geol 32: $39-61$

Pinckney J, Paerl HW, Reid RP, Bebout B (1995) Ecophysiology of stromatolitic microbial mats, Stocking Island, Exuma Cays, Bahamas. Microb Ecol 29:19-37

Renaut RW (1993) Morphology, distribution and preservation potential of microbial mats in the hydromagnesite-magnesite playas of the Cariboo Plateau, BC, Canada. Hydrobiologia 267:75-98

Editorial responsibility: Karel Simek, Ceské Budějovice, Czech Republic
Romani AM, Sabater S (1997) Metabolism recovery of a stromatolitic biofilm after drought in a Mediterranean stream. Arch Hydrobiol 140:261-271

Romani AM, Sabater S (1998) A stromatolitic cyanobacterial crust in a Mediterranean stream optimizes organic matter use. Aquat Microb Ecol 16:131-141

Sabater S (1989) Encrusting algal assemblages in a Mediterranean river basin. Arch Hydrobiol 114:555-573

Sabater F, Guasch H, Martí E, Armengol J, Sabater S (1995) The Ter: a Mediterranean river case-study in Spain. In: Cushing CE, Cummins KW, Minshall GW (eds) River and stream ecosystems. Elsevier, Amsterdam, p 419-438

Sabater S, Guasch H, Romaní A, Mun̄oz I (2000) Stromatolitic communities in Mediterranean streams: adaptations to a changing environment. Biodivers Conserv 9:379-392

Schuessler A, Meyer T, Gehrig H, Kluge M (1997) Variations of lectin binding sites in extracellular glycoconjugates during the life cycle of Nostoc punctiforme, a potentially endosymbiotic cyanobacterium. Eur.J Phycol 32:23.3-23.9

Stal LJ (1995) Physiological ecology of cyanobacteria in microbial mats and other communities. New Phytol 131:1-32

Stevenson RJ, Glover R (1993) Effects of algal density and current on ion transport through periphyton communities. Limnol Oceanogr 38:1276-1281

Stoodley P, de Beer D, Lewandowski Z (1994) Liquid flow in biofilm systems. Appl Environ Microbiol 60:2711-2716

Verrecchia E, Yair A, Kidron GJ, Verrecchia K (1995) Physical properties of the psammophile cryptogamic crust and their consequences to the water regime of sandy soils, northwestern Negev Desert, Israel. J Arid Environ 29:427-437

Williams DD (1987) The ecology of temporary streams. Croom Helm, London

Winsborough BM, Golubic S (1987) The role of diatoms in stromatolite growth: two examples from modern freshwater settings. J Phycol 23:195-201

Wolfaardt GM, Lawrence JR, Robarts RD, Caldwell DE (1998) In situ characterization of biofilm exopolymers involved in the accumulation of chlorinated organics. Microb Ecol 35: $213-223$

Submitted: August 11, 1999; Accepted: December 7, 1999 Proofs received from author(s): February 28, 2000 